\title{
Tuberculosis risk in the biologic era: tuberculin skin test conversion rates in children with rheumatologic diseases
}

\author{
Canan Özlü̈ ${ }^{1 \oplus}$, Serkan Türkuçar ${ }^{2 \oplus}$, Hatice Karaoğlu Asrak ${ }^{1 \oplus,}$ \\ Hatice Adıgüzel Dündar ${ }^{2 \oplus}$, Şevket Erbil Ünsal ${ }^{2 \oplus}$, Nurşen Belet ${ }^{1 \oplus}$ \\ Divisions of ${ }^{1}$ Pediatric Infectious Diseases and ${ }^{2}$ Pediatric Rheumotology, Department of Pediatrics, Dokuz Eylul University Faculty of \\ Medicine, Izmir, Turkey.
}

\begin{abstract}
Background. The widespread use of biological treatments has increased the frequency of opportunistic infections such as tuberculosis (TB). The primary objective of our study was to determine the rate of tuberculin skin test (TST) conversion during biological therapy. The secondary objective was to monitor the side effects related to isoniazid (INH) prophylaxis, in the selected subgroup.

Methods. Children with rheumatologic diseases receiving treatment with tumor necrosis factor-alpha (TNF- $\alpha$ ) inhibitors, and tocilizumab and canakinumab were included in the study. If baseline screening was negative, TST was performed annually after initiation of biologic therapy. TST conversion was accepted as an increase of at least $6 \mathrm{~mm}$ and becoming positive or an increase of $10 \mathrm{~mm}$ or more, even in the absence of positivity.
\end{abstract}

Results. 121 patients (female n: 63, 52\%) were included in the study. The mean follow-up period was $26.10 \pm 14.8$ months. 85 of the patients were using TNF- $\alpha$ inhibitors and 18 tocilizumab, and 18 canakinumab. Forty patients had positive TST before biological agents and received chemoprophylaxis with INH. The rate of TST conversion among the 3 biological agents was not statistically significant (20.4\% of TNF- $\alpha$ inhibitors, $25 \%$ of canakinumab and $33.3 \%$ of tocilizumab users). All patients with LTBI received INH prophylaxis, and none of them had active TB.

Conclusions. There was no statistically significant difference among the three biological agents, regarding the seroconversion rates. Patients receiving tocilizumab and canakinumab should also be screened for TB during follow-up. INH related side effects are rare.

Key words: biological agents, tuberculosis, children, TNF- $\alpha$ inhibitors, tocilizumab, canakinumab.

Tuberculosis (TB) is a common infectious disease worldwide. Up to one-third of the world's population is estimated to be infected with Mycobacterium tuberculosis, $5-10 \%$ of infected persons will develop active TB disease over their lifetime. In the remaining cases, the bacteria maintain a dormant state without clinical evidence of active TB disease for many years, namely, latent TB infection (LTBI). ${ }^{1}$ The main step in TB elimination is the identification of LTBI and inhibition of reactivation with

$凶$ Canan Özlü

drcananozlu@gmail.com

Received 9th March 2021, revised 28th April 2021, 8th May 2021, accepted 13th May 2021. prophylaxis. $^{2}$ The risk for active TB disease after infection depends on several factors, such as increased age and children under five, HIV infection, or other immunosuppressive diseases, and/or drugs like biological agents. ${ }^{3}$

Biological agents provide significant treatment advances in several autoimmune and autoinflammatory diseases in children. ${ }^{4}$ Treatment with biologic agents, in particular tumor necrosis factor-alpha (TNF- $\alpha$ ) inhibitors, is associated with an increased risk of TB. Therefore, screening and treatment for LTBI in patients receiving TNF- $\alpha$ inhibitors are mandatory. ${ }^{2}$ Previous studies from Turkey have reported a 10-20 fold increase in the 
risk of reactivation of LTBI in patients treated with TNF- $\alpha$ inhibitors. ${ }^{5}$ Biological agents other than TNF- $\alpha$ inhibitors also cause immunosuppression, and can increase the risk of TB. The use of interleukin (IL)-6/ IL-6 receptortargeted agents (tocilizumab and siltuximab) is associated with an increased risk of TB similar to that observed in TNF- $\alpha$ inhibitors. European Society of Clinical Microbiology and Infectious Diseases Study Group for Infections in Compromised Hosts recommends TB screening in adult tocilizumab users, like TNF- $\alpha$ inhibitors, but does not recommend of those taking IL-1-targeted (anakinra, canakinumab or rilonacept) agents, as the risk of $\mathrm{TB}$ with these drugs is reported as "moderate". ${ }^{6}$ The guidelines for TB screening in children using biological agents are only available for TNF- $\alpha$ inhibitors, and there is no recommendation for TB screening in children receiving tocilizumab and canakinumab.

Our national guidelines recommend TB screening in children receiving TNF- $\alpha$ inhibitors with a medical history, chest radiogram, tuberculin skin test (TST) and/or interferon-gamma release assay (IGRA) before the initiation of TNF- $\alpha$ inhibitors and according to these guidelines children with negative baseline screening test should be rescreened annually with TST and/or IGRA. ${ }^{5}$ Despite the regular use of this screening test, the prevalence of TB in patients receiving biological agents is higher than that of the general population., $3,7-9$ In 2017, Cuomo et al. ${ }^{3}$ investigated the rate of TB screening test conversion during biological therapy in rheumatic patients with negative baseline screening. There are only a few adult and child studies that investigated the ratio of TB screening test conversion during anti-TNF therapy in rheumatic patients with negative baseline screening ${ }^{3,7-13}$, no studies reported the results of rescreening $\mathrm{TB}$ in children treated with canakinumab and tocilizumab.

Our study aimed to determine the rate of TST conversion in children receiving biological agents (TNF- $\alpha$ inhibitors, canakinumab, tocilizumab), and the second aim was monitoring the side effects related to isoniazid (INH) prophylaxis.

\section{Material and Methods}

Our study was conducted at Dokuz Eylul University Hospital (a tertiary-care pediatric center), between January 2014 and January 2019. We evaluated all children with rheumatic diseases. One hundred and twenty-one patients who had been given biological agents for at least 12 months, were included in this retrospective study. Patients with a history of TB or LTBI, baseline findings suggestive of old or active TB, previous treatment with anti-TB and biological agent were excluded from the study.

The demographic and clinical characteristics (age, gender, type and duration of the underlying disease, type and drug usage duration of immunosuppressive drugs and biological agent treatment) of the 121 patients were recorded. All patients were routinely screened for TB infection before biological agent initiation. They were questioned for possible TB history (close contacts, signs and symptoms consistent with $\mathrm{TB}$ ) in their families. Patients were physically examined, TST was performed and a chest radiograph was taken. At initial screening, TST with a $<5$ $\mathrm{mm}$ of induration in immunosuppressed, $<10$ $\mathrm{mm}$ in non-immunosuppressed children were accepted as negative, according to the national guideline for diagnosis and treatment of TB. ${ }^{5}$ Patients with LTBI at initial TB screening were given prophylaxis with INH for 9-12 months. In this group, $\mathrm{TB}$ screening was continued with clinical evaluation in every three months and radiological evaluation with chest radiograph in every 6 months. Children with negative baseline TB screening were additionally screened with an annual TST. TST conversion was accepted as TST increase of at least $6 \mathrm{~mm}$ and becoming positive, or TST increase of $10 \mathrm{~mm}$ or more even if the absence of positivity. 5,13

All children with converted TST were administered prophylaxis with INH (10-20 mg/ 
$\mathrm{kg} /$ day, maximum $300 \mathrm{mg} /$ day) after excluding active TB for 9-12 months. ${ }^{14}$ After one month of INH prophylaxis, biological agents were implemented if indicated. Transaminase levels were evaluated every 3 months during INH prophylaxis.

Statistical analyses were performed using SPSS 24.0. Categorical variables were shown as percentages, mean values of continuous variables as normal and $\pm 2 \mathrm{SD}$ (standard deviation) values, and non-normally distributed values as median and quartiles (IQR: interquartile range). The relationship between categorical variables and dependent variables were analyzed by chi-square and Fisher's exact test when chi-square assumptions were not met. Statistical significance limit was accepted as $\mathrm{p}<0.05$

\section{Results}

One hundred and twenty-one children (63 females) with rheumatic diseases (mean age: $154.35 \pm 51.3$ months) were treated with a biological agent. The mean follow-up period was 26.10 $\pm 14,84$ months (median 24; range $12-60$ months). Adalimumab was the most commonly prescribed drug $(43 \%)$, followed by etanercept $(21.5 \%)$, canakinumab $(14,9 \%)$ and tocilizumab (14.9\%). 114 patients used one biological agent, 7 patients switched to another biological agent due to insufficient clinical response. In all 7 (5.8\%) patients, switch was performed to adalimumab from etanercept. Juvenile idiopathic arthritis (JIA) was the most frequent indication for a biological agent treatment 95 (78.5\%); other indications were autoinflammatory diseases $17 \quad(14 \%)$ and uveitis $7(0.05 \%)$ and one patient had Farber disease. Table I presents the data concerning the demographic, clinical and therapeutic features of the 121 patients.

The prevalence of LTBI in our population at the initiation of biological treatment was $33 \%$ (40/121). Forty patients had positive TST results (31 TNF- $\alpha$ inhibitors, 6 canakinumab,
3 tocilizumab) and all positive patients were treated with INH for 9-12 months with a diagnosis of LTBI.

Among 81 children using biological therapy and undergoing rescreening for $\mathrm{TB}, 54(66.6 \%)$ were initially treated with anti-TNF, $12(14.8 \%)$ with canakinumab, and 15(18.5\%) with tocilizumab. Four $(4.9 \%)$ children were switched to adalimumab from etanercept. At the time of the initial TB screening of 81 children, $63 \%$ of patients were receiving methotrexate (minimum three months duration), $5 \%$ steroids $(2 \mathrm{mg} / \mathrm{kg}$,

Table I. Demographic, clinical and therapeutic characterics at initial evaluation in children receiving biological agents.

\begin{tabular}{|c|c|}
\hline Variable & $\begin{array}{l}\text { Number of } \\
\text { patients } \\
\mathrm{n}(\%)\end{array}$ \\
\hline Male sex & $58(48)$ \\
\hline Follow up period, months, median & $26.10 \pm 14$ \\
\hline Positive history of $\mathrm{TB}$ contact & $3(0,02)$ \\
\hline \multicolumn{2}{|l|}{ Disease } \\
\hline JIA & 95 \\
\hline Polyarticular JIA & 36 \\
\hline Oligoarticular JIA & 25 \\
\hline Systemic JIA & 8 \\
\hline Enthesitis-related arthritis & 21 \\
\hline JPA & 5 \\
\hline Autoinflammatory diseases & 17 \\
\hline FMF & 12 \\
\hline HIDS & 4 \\
\hline CAPS & 1 \\
\hline Uveitis & 7 \\
\hline Farber Disease & 1 \\
\hline \multicolumn{2}{|l|}{ Biological agents } \\
\hline TNF- $\alpha$ inhibitors & 85 \\
\hline Adalimumab & 52 \\
\hline Etanercept & 26 \\
\hline Etanercept+ Adalimumab & 7 \\
\hline IL-1 Inhibition (Canakinumab) & 18 \\
\hline IL-6 Inhibition (Tosilizumab) & 18 \\
\hline
\end{tabular}

JIA: juvenile idiopathic arthritis, JPA: juvenile psoriatic arthritis, FMF: Familial mediterranean fever, HIDS: hyper IgD syndrome, CAPS: cryopyrin-associated periodic syndromes, TNF: tumor necrosis factor, IL:interleukin 
maximum $60 \mathrm{mg} /$ day after pulse steroid in the last month), $5 \%$ both steroids and methotrexate. The characteristics of 81 patients in the study are summarized in Table II.

During the annual screening of TB, 19 (23.4\%) cases that were initially TST negative became positive, the time interval was 12-60 months $(26.85 \pm 13.83)$. The conversion was observed as $20.4 \%(11 / 54)$ for TNF- $\alpha$ inhibitors and $33.3 \%(3 / 12)$ for canakinumab and 30\% (5/15) for tocilizumab. No difference was found between biological agent types in terms of
TST conversion rates. $(\mathrm{p}=0.57)$ (Fig. 1$)$. None of these patients had symptoms of TB. Active $\mathrm{TB}$ was excluded in these converted cases by history, physical examination and chest radiography. All converted patients received INH prophylaxis. No patients developed active TB. Detailed information about seroconverted patients are given in Table III.

The factors that may affect TST conversion were also evaluated. There were statistically no difference between the converters and nonconverters in terms of gender $(p=0.28)$, age

Table II. Characteristics of 81 patient (converters and nonconverters)

\begin{tabular}{lllll}
\hline Characteristics & $\begin{array}{l}\text { Total } \\
(\mathrm{n}: 81)\end{array}$ & $\begin{array}{l}\text { Converters } \\
(\mathrm{n}: 19)\end{array}$ & $\begin{array}{l}\text { Nonconverters } \\
(\mathrm{n}: 62)\end{array}$ & p value \\
\hline Sex (M/F) & $34 / 47$ & $10 / 9$ & $24 / 38$ & 0.28 \\
Age (months), mean \pm SD & $154.35 \pm 51.35$ & $157.30 \pm 52.25$ & $153.44 \pm 51.47$ & 0.51 \\
Disease duration (months), mean \pm SD & $67.52 \pm 51.35$ & $61.69 \pm 42.6$ & $69.30 \pm 42.32$ & 0.44 \\
Follow-up duration (months), mean \pm SD & $26.85 \pm 13.83$ & $31.78 \pm 11.40$ & $25.33 \pm 14.23$ & 0.17 \\
Type of biologic agents & & & & 0.57 \\
TNF- $\alpha$ inhibitors & 54 & 11 & 43 & \\
$\quad$ Adalimumab & 31 & 6 & 25 & \\
$\quad$ Etanercept & 19 & 3 & 16 & \\
$\quad$ Etanercept+ Adalimumab & 4 & 2 & 2 & \\
IL-1 Inhibition (Canakinumab) & 12 & 3 & 9 & \\
IL-6 Inhibition (Tosilizumab) & 15 & 5 & 10 & \\
Concomittant treatment & 59 & 12 & 47 & \\
Steroid & 4 & 1 & 3 & \\
Methotrexate & 51 & 9 & 42 & \\
Steroid+ Methotrexate & 4 & 2 & 2 & \\
\hline
\end{tabular}

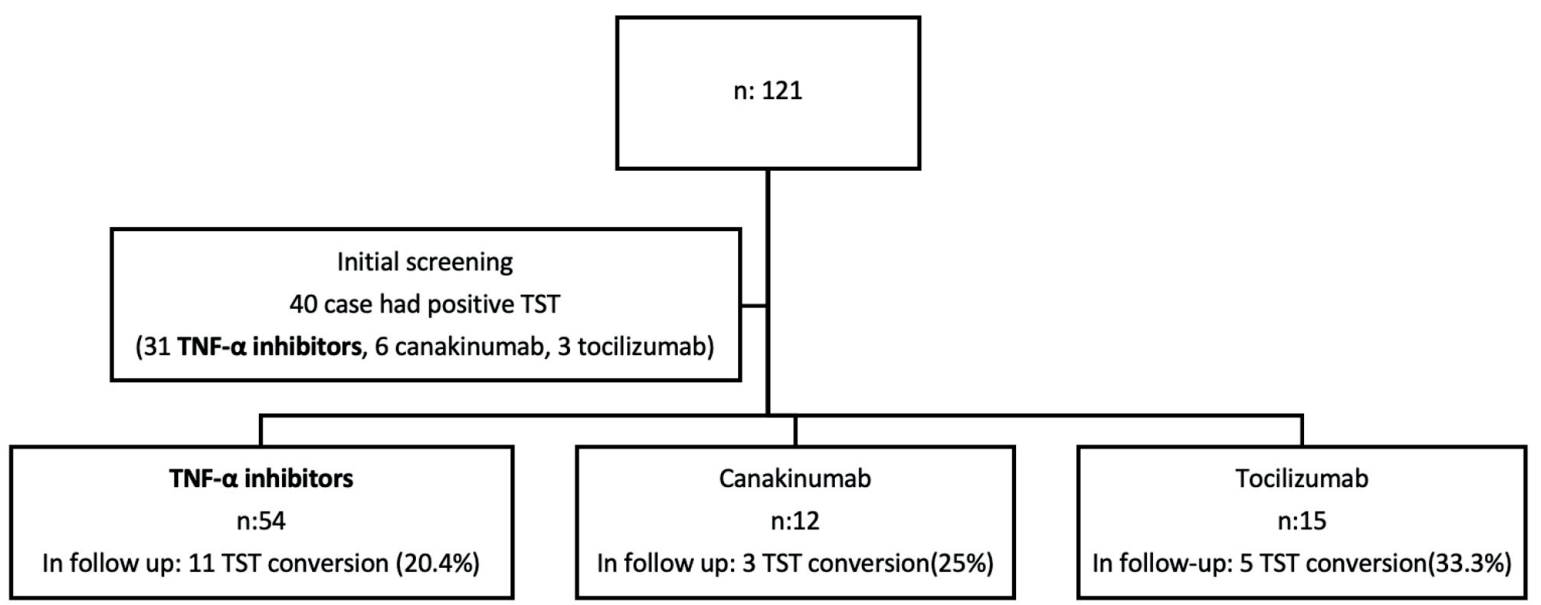

Fig. 1. Tuberculosis screening in children on biological agent therapies. 


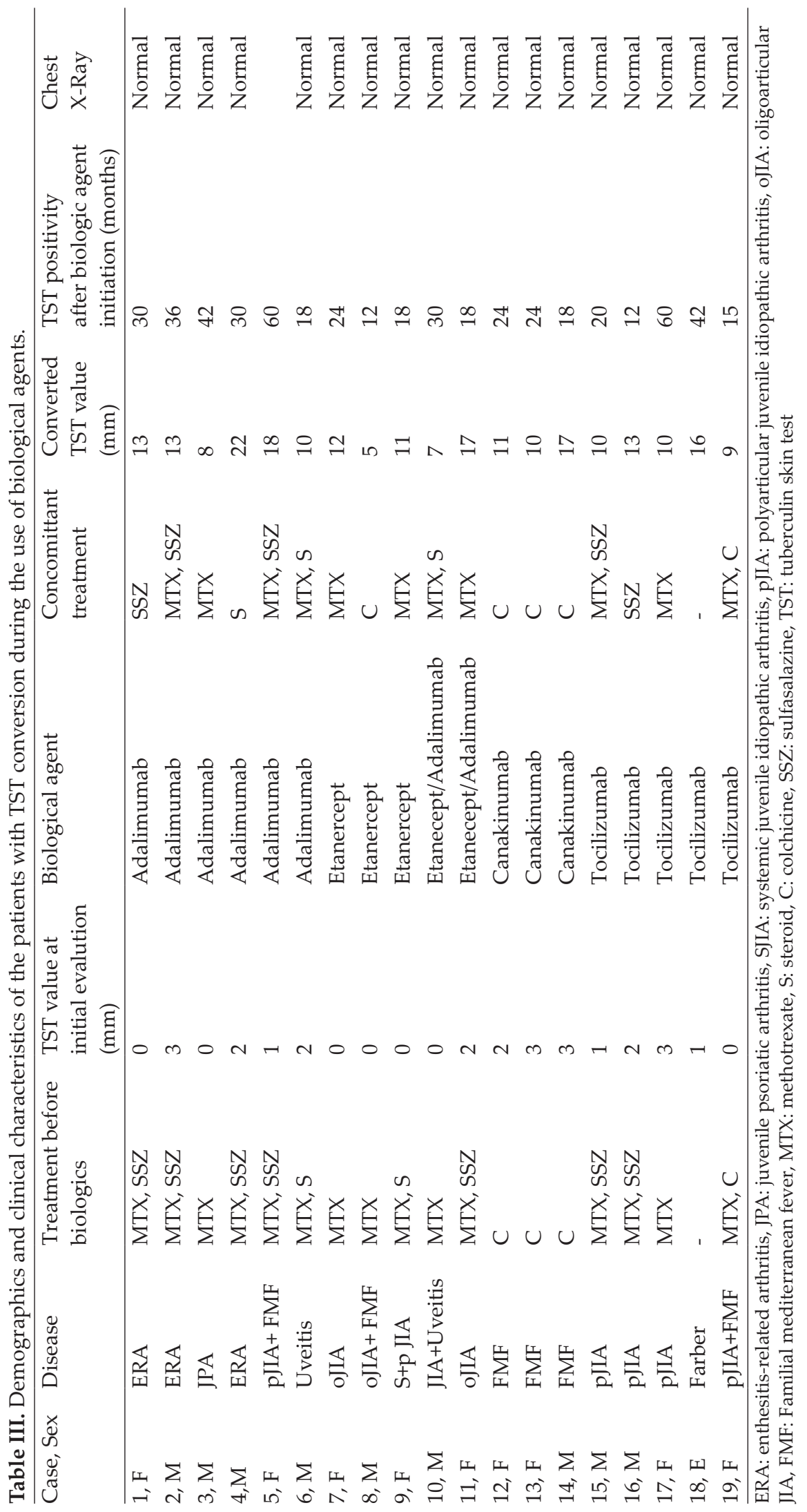


$(p=0.51)$, type of disease $(p=0.46)$, duration of primary disease $(\mathrm{p}=0.44)$, type of biological agent $(\mathrm{p}=0.57)$, and concomitant therapy $(\mathrm{p}=0.52)$ with steroid, methotrexate, steroid and methotrexate treatment in addition to a biological agent.

A total of 59 patients received prophylaxis with INH. Since 49 of the cases were over $30 \mathrm{~kg}$, they received the maximum dose of $300 \mathrm{mg} \mathrm{INH}$, while the other ten patients received $10-20 \mathrm{mg} /$ $\mathrm{kg}$ /day INH. TB disease did not develop in any of the patients who received prophylaxis. One-and-a-half-fold increase in transaminase level was observed in only one patient during INH treatment, it spontaneously regressed, no discontinuation was required.

A 7-year-old girl, who was on canakinumab every 4 weeks for hyperimmune globulin D syndrome (HIDS), developed pneumonia, which did not respond to broad-spectrum antibiotics therapy at the 46th month of canakinumab. Her TST was $0 \mathrm{~mm}$ and IGRA was negative. Sputum acid-fast bacilli staining and TB culture were negative. Thorax computed tomography showed lymph nodes at right paratracheal, subcarinal and bilateral hilar, ground-glass opacities and centraciner nodules (budding tree appearance) more prominent in the lower lobes of both lungs. The patient was considered as probable TB and antituberculous treatment was started. The patient improved with antituberculous therapy. Canakinumab was discontinued. In the third month of TB treatment, the patient had to take steroids because of HIDS attack. TB treatment was completed after 12 months. Reactivation was not observed at 24th-month follow-up.

\section{Discussion}

This is the first study in literature examining and comparing the conversion rate of TST receiving different types of biological therapies in children. TST conversion rate was $23.5 \%$ in this study and no difference was observed in TST conversion rates during the use of different types of biological agents, and TB screening should be performed annually in children using tocilizumab and canakinumab, as in anti-TNF users.

So many guidelines, including our own national guidelines, have recommended repeated TB screening in anti-TNF users. There are as yet few studies investigating the performance of rescreening in patients receiving anti-TNF agents. ${ }^{13}$ The rate of conversion ranged from $0-37 \%$ for the TST while using anti-TNFs. ${ }^{8,15-19}$ In general, the rate of conversion was higher in high-TB-prevalence countries. For example, the conversion rate of TST was $0-12 \%$ in lowprevalence countries increasing to $25-37 \%$ in high-prevalence areas. ${ }^{3}$

There are only two studies on TST conversion in children using anti-TNF in Turkey. In the study of Acar et al. ${ }^{11}$ thirty-two children were given INH treatment for LTBI and 16 (21.9\%) of them were started during follow-up. In a study reported by Kıliç et al. ${ }^{12}, 14.5 \%$ of the patients had been diagnosed as LTBI initially and $4.8 \%$ were started on INH during followup. The ratio in the first study was similar to ours $(20.4 \%)$, the second study's ratio was lower attributable to their approach of taking the TST cut-off limit as $10 \mathrm{~mm}$.

No studies have reported TST conversion in children treated with canakinumab and tocilizumab. Cuomo et al. ${ }^{3}$ reported TST conversion in tocilizumab users as $15.9 \%$, this rate which was lower than ours (33\%), which may be due to BCG vaccination status and differences in prevalence between countries for TB and age groups. Very limited experience has been attained with the use of IL-1-targeted agents in patients with LTBI. ${ }^{6}$ In a study from Turkey, it was reported that INH prophylaxis was given in 4 out of 15 children receiving canakinumab for FMF during a 24-month follow-up period because of TST positivity in rescreening. ${ }^{20}$ This ratio is similar to ours' $(25 \%)$.

The reason and clinical significance of this conversion have not been revealed yet. It remains to be clarified whether these results indicate true positive conversion signs of an underlying LTBI, false-positive results or 
false-negative initial screening results due to using immunosuppressives such as steroid and methotrexate in children suffering from rheumatic diseases. In the study by Kiray et al. $^{21}$ comparing TST response in children with JIA and healthy controls, TST positivity was seen at a lower rate in children with JIA compared to healthy controls due to use of immunosuppressives.

Risk factors that may cause TB test conversion in children using biological agents were evaluated. Longer disease duration, male gender, and older age have been shown to increase TST conversion rates ${ }^{3,10}$, but we determined that age, gender, disease type, duration of primary disease, and biological agent type do not affect TST conversion rates.

Our second conclusion from this study is that the rate of transaminase elevation, which can be seen as a side effect due to INH, is low. INHinduced transaminase elevation has been shown in patients using TNF- $\alpha$ inhibitors without severe permanent liver damage. ${ }^{22}$ Mutlu et al. ${ }^{23}$ reported that hepatotoxicity rate related to INH prophylaxis was $17.3 \%$ in 196 adult patients receiving TNF- $\alpha$ inhibitors and INH treatment was discontinued due to progressive hepatotoxicity in 5\% of cases. Hepatotoxicity rate was $1.3 \%$ due to INH in children receiving TNF- $\alpha$ inhibitors. ${ }^{11}$ In this study, one $(0.08 \%)$ patient had an increase in transaminase that did not require treatment interruption during INH prophylaxis and liver enzymes regressed in follow-up.

Finally, this study has some limitations and results need to be evaluated in this context. Limitations are its retrospective design and relatively small number of patients. All risk factors of TB (vitamin D status, malnutrition, etc) have not been studied. IGRA test was lacking because of its high cost. However, this study is important because it is the first study evaluating the TST conversion rates in pediatric cases using different types of biological agents. Further studies with larger sample sizes are needed to confirm our findings.
In conclusion, $\mathrm{TB}$ should be screened not only for those using TNF- $\alpha$ inhibitors but also for other biological agents (canakinumab, tocilizumab) in children with rheumatological disease, especially in an intermediate TB burden area such as Turkey. New TB monitoring guidelines should be established during biological therapy.

\section{Author contribution}

The authors confirm contribution to the paper as follows: study conception and design: CÖ; data collection: CÖ, HKA, HAD, ST; analysis and interpretation of results: CÖ, HKA; draft manuscript preparation: CÖ, NB, ŞEÜ. All authors reviewed the results and approved the final version of the manuscript.

\section{Ethical approval}

Approved by Dokuz Eylül University Medical Faculty Non-invasive Ethical Committee with the decision number 2021/03-46.

\section{Source of funding}

No funding was required.

\section{Conflict of interest}

There is no conflict of interests.

\section{REFERENCES}

1. World Health Organization (WHO). Latent tuberculosis infection: updated and consolidated guidelines for programmatic management. Geneva, Switzerland: World Health Organization, 2018. Available at: https://apps.who.int/iris/bitstream/han dle/10665/260233/9789241550239-eng.pdf (Accessed on June 30, 2020).

2. Dobler CC. Biologic agents and tuberculosis. Microbiol Spectr 2016; 4: TNMI7-0026-2016. https:// doi.org/10.1128/microbiolspec.TNMI7-0026-2016

3. Cuomo G, D'Abrsca V, Iacono D, Pantano I. The conversion rate of tuberculosis screening tests during biological therapies in patients with rheumatoid arthritis. Clin Rheumatol 2017; 36: 457-461. https:// doi.org/10.1007/s10067-016-3462-z 
4. Woerner A, Ritz N. Infections in children treated with biological agents. Pediatr Infect Dis J 2013; 32: 284288. https://doi.org/10.1097/INF.0b013e3182833cbb

5. T.C. Sağlık Bakanlığı. Tüberküloz Tanı ve Tedavi Rehberi. Ankara, 2019. Available at: https://hsgm. saglik.gov.tr/depo/birimler/tuberkuloz_db/ haberler/Tuberkuloz_Tani_Ve_Tedavi_Rehberi_/ Tuberkuloz_Tani_ve_Tedavi_Rehberi.pdf (Accessed on July 9, 2019).

6. Winthrop KL, Mariette X, Silva JT, et al. ESCMID Study Group for Infections in Compromised Hosts (ESGICH) Consensus Document on the safety of targeted and biological therapies: an infectious diseases perspective (Soluble immune effector molecules [II]: agents targeting interleukins, immunoglobulins and complement factors). Clin Microbiol Infect 2018; 24(Suppl 2): S21-S40. https:// doi.org/10.1016/j.cmi.2018.02.002

7. Keystone EC, Papp KA, Wobeser W. Challenges in diagnosing latent tuberculosis infection in patients treated with tumor necrosis factor antagonists. J Rheumatol 2011; 38: 1234-1243. https://doi. org/10.3899/jrheum.100623

8. Park JH, Seo GY, Lee JS, Kim TH, Yoo DH. Positive conversion of tuberculin skin test and performance of interferon release assay to detect hidden tuberculosis infection during anti-tumor necrosis factor agent trial. J Rheumatol 2009; 36: 2158-2163. https://doi.org/10.3899/jrheum.090150

9. Sanduzzi A, Bocchino M, Atteno M, et al. Screening and monitoring of latent tubercular infection in patients taking tumor necrosis factor- $\alpha$ blockers for psoriatic arthritis. J Rheumatol Suppl 2012; 89: 82-85. https://doi.org/10.3899/jrheum.120252

10. Cerda OL, de los Angeles Correa M, Granel A, et al. Tuberculin test conversion in patients with chronic inflammatory arthritis receiving biological therapy. Eur J Rheumatol 2019; 6: 19-22. https://doi. org/10.5152/eurjrheum.2018.18096

11. Acar M, Sütçü M, Aktürk $H$, et al. Tuberculosis screening in pediatric patients receiving TNF-alpha inhibitor therapy. Turk J Pediatr 2017; 59: 503-510. https://doi.org/10.24953/turkjped.2017.05.001

12. Kilic O, Kasapcopur O, Camcioglu Y, Cokugras H, Arisoy N, Akcakaya N. Is it safe to use anti-TNF- $\alpha$ agents for tuberculosis in children suffering with chronic rheumatic disease? Rheumatol Int 2012; 32: 2675-2679. https://doi.org/10.1007/s00296-011-2030-8

13. Hatzara C, Hadziyannis E, Kandili A, et al. Frequent conversion of tuberculosis screening tests during anti-tumour necrosis factor therapy in patients with rheumatic diseases. Ann Rheum Dis 2015; 74: 1848-1853. https://doi.org/10.1136/ annrheumdis-2014-205376
14. American Thoracic Society. CDC targeted tuberculin testing and treatment of latent tuberculosis infection. Am J Respir Crit Care Med 2000; 161(4 Pt 2): S221-S247. https://doi.org/10.1164/ajrccm.161. supplement_3.ats600

15. Garcovich S, Ruggeri A, D’Agostino M, et al. Clinical applicability of Quantiferon-TB-Gold testing in psoriasis patients during long-term anti-TNF-alpha treatment: a prospective, observational study. J Eur Acad Dermatol Venereol 2012; 26: 1572-1576. https:// doi.org/10.1111/j.1468-3083.2011.04220.x

16. Chen DY, Shen GH, Hsieh TY, Hsieh CW, Lan JL. Effectiveness of the combination of a whole-blood interferon-gamma assay and the tuberculin skin test in detecting latent tuberculosis infection in rheumatoid arthritis patients receiving adalimumab therapy. Arthritis Rheum 2008; 59: 800-806. https:// doi.org/10.1002/art.23705

17. Hatemi G, Melikoglu M, Ozbakir F, Tascilar K, Yazici H. Quantiferon-TB Gold in tube assay for the screening of tuberculosis before and during treatment with tumor necrosis factor alpha antagonists. Arthritis Res Ther 2012; 14: R147. https://doi.org/10.1186/ar3882

18. Papay P, Primas C, Eser A, et al. Retesting for latent tuberculosis in patients with inflammatory bowel disease treated with TNF- $\alpha$ inhibitors. Aliment Pharmacol Ther 2012; 36: 858-865. https:/doi. org/10.1111/apt.12037

19. Scrivo R, Sauzullo I, Mengoni F, et al. Mycobacterial interferon $-\gamma$ release variations during longterm treatment with tumor necrosis factor blockers: lack of correlation with clinical outcome. J Rheumatol 2013; 40: 157-165. https://doi.org/10.3899/jrheum.120688

20. Gülez N, Makay B, Sözeri B. Long-term effectiveness and safety of canakinumab in pediatric familial Mediterranean fever patients. Mod Rheumatol 2020; 30: 166-171. https://doi.org/10.1080/14397595.2018.15 59488

21. Kiray E, Kasapcopur O, Bas V, et al. Purified protein derivative response in juvenile idiopathic arthritis. J Rheumatol 2009; 36: 2029-2032. https://doi. org/10.3899/jrheum.090173

22. Hanta I, Ozbek S, Kuleci S, Sert M, Kocabas A. Isoniazid intervention for latent tuberculosis among 86 patients with rheumatologic disease administered with anti-TNFalpha. Clin Rheumatol 2007; 26: 18671870. https://doi.org/10.1007/s10067-007-0591-4

23. Mutlu P, Sevinç C, Uz Kılınç O, Uçan ES. Anti-TNFalfa tedavisi verilen olgularda latent tüberküloz infeksiyonu açısından izlem sonuçlarımız. Nobel Medicus 2014; 10: 47-52. 